\title{
The Impact of Extracurricular Activities on Language Learning: 'Access Program' in Morocco as a Case Study
}

\author{
Said Aoujil1 $1 \mathrm{D} \triangle$, Driss Benattabou² (iD \\ ${ }^{1}$ Part-time Teacher of English, Department of English, Faculty of Arts and Humanities, Moulay Ismail University, Meknes, Morocco \\ ${ }^{2}$ Professor of English at the Department of English, Faculty of Arts and Humanities, Moulay Ismail University, Meknes, Morocco \\ $\triangle$ Corresponding Author: Said Aoujil, E-mail: s.aoujil@gmail.com
}

ARTICLE INFORMATION ABSTRACT

Received: December 14, 2020

Accepted: February 11, 2021

Volume: 4

Issue: 2

DOI: $10.32996 /$ ijllt.2021.4.2.22

\section{KEYWORDS}

Experimental study, descriptive statistics, EFL learning,

extracurricular activities
The objective of the present study is to investigate the role of 'Access Program' in enhancing the achievement levels of EFL students in Morocco. The study is an experimental one consisting essentially of two groups: experimental and control groups. The experimental group received the treatment of engaging students in the different 'Access Program' activities. The control group was made up of students of the same level as the experimental group, but lacking the activities of the 'Access Program'. When the program was over, the two groups underwent the same test. The findings showed that the 'Access Program' students outperformed the 'Non-Access' students in different language skills. The paper ends up with a conclusion along with some practical recommendations for practitioners in the field to incorporate the use of these extracurricular activities.

\section{Introduction}

The Ministry of Education in Morocco has recently started seeking some ways to enhance the quality of learning in general by making many reforms in schedules and through looking for partners to assist them in this enterprise. It signed an agreement for partnership and cooperation with some associations, among of which The Moroccan Association of Teachers of English (MATE) aiming to improve education and training in Morocco.

The American Embassies started a micro scholarship program called 'Access' for teaching English and American Culture in 70 countries throughout the world, particularly in Africa and the Middle East, to students who belong to underprivileged families. The objective of the program is to teach every Sunday morning four hours of English courses along with some enhancement activities using ICT (Information Communication Technologies) to groups of 15 to 24 students. The first two hours are devoted to English studies while the second two hours are concerned with the teaching of some enhancement activities including but not limited to games, drama, and songs.

The program lasts for two years. Students join the program for free, and they are offered books, copybooks, readers and pens. In addition to that, students are offered a breakfast meal and they are reimbursed if they use transport to attend these classes.

\subsection{The Purpose of the Study}

The aim of this study is to investigate to what extent extracurricular activities empower the quality of English language learning among students of underprivileged families. Another objective of this research is to examine these students' attitude towards this 'Access program', and to see whether they would benefit from their exposure to it.

\subsection{Research Question}

- Does access microscholarship program, which includes a set of extracurricular activities, empower English language learners?

\section{K C AL-KINDI CENTER $\mathbf{R}$ FOR RESEARCH AND DEVELOPMENT Your gateway to world-class research}

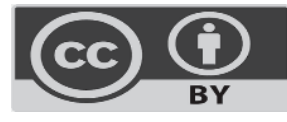

Published by Al-Kindi Center for Research and Development. Copyright (c) the author(s). This open access article is distributed under a Creative Commons Attribution (CC-BY) 4.0 license 


\subsection{Hypothesis}

- $\quad$ Access program promotes the achievement level of EFL students.

\section{Review of Literature}

Communicating effectively in a foreign language is often considered as an activity that can be developed in the classroom context. To achieve this purpose, teachers are commonly encouraged to expose their students to a number of language teaching materials which stress a combination of both the verbal as well as the non-verbal sides of the foreign language. Although there is some truth in this, a number of other practitioners in the field are more inclined to contend that along these two fundamental and inextricable aspects of the foreign language, language learning could be best activated and triggered through a host of other more rewarding extracurricular activities.

According to this vision, students ought to be involved in learning environments in which a variety of social interaction forms could make them aware of different linguistic forms and communication contexts. Vygotsky (1987) contends in this respect that social interaction enhances language development and helps promote learners' ability to construct meaningful knowledge. These enhancement activities seem to play a vital role in motivating students to engage in different meaningful learning tasks. They have a great impact on both cognition and personality building. Although practitioners have discussed a wide range of these extracurricular activities, the following theoretical background will consider only three of them, namely songs, drama and games.

\subsection{Enhancement Activities}

\subsubsection{Songs}

Researchers argue that enhancement activities play an important role in improving language learning abilities. Medina (2003) states that music and songs could be used as very effective means to enhance students' language skills. Brand \& Li (2009) seem to maintain the same idea arguing that songs could be exploited to facilitate the task for second-language learners. In the same vein, Wray \& Perkins (2000) argue that most speech in songs involve repetition and variation of memorized formulas that may help in the process of language learning.

Lam Choi Ling's study (2009) in Hong Kong substantiates the same contention delineating the importance of using songs in a primary school through an activity entitled "I can program". Students have been observed to display a great appreciation in the use of songs at the early ages of learning languages. Relying on the implementation of semi-structured interviews, all the teachers have been found to have a positive attitude towards the use of songs in English language teaching as they assist in motivating the students and tend to create a free- anxiety atmosphere for them.

Other researchers have stressed the importance of implementing songs as a useful medium to develop students' listening skill. Sevik (2012) conducted a research in order to examine the utility of incorporating songs as listening activities to improve learners' abilities in EFL classes. He found out that songs help in engaging learners in meaningful situations. This, according to him, can work effectively if the tasks are well selected.

Arévalo (2010) investigated students' listening performance through the use of six workshops based on songs. He concluded that songs are "the most suitable type of authentic material to develop listening comprehension"(p.130). He adds that implementing songs boosts not only students' motivation, but their attention spans as well. He confirms the idea that through songs, students are found to be more excited, willing to participate, and familiar with native speakers' pronunciation.

\subsubsection{Drama}

Janudom and Wasanasonsithi (2009) carried out a study in Thailand aiming to find the role of Drama and questioning techniques in enhancing students' achievement. Students have also been examined regarding their attitudes towards English instruction employing the integration of drama and questioning techniques. For the purposes of this study, a group of university students were exposed to a seven-week English instruction using a Drama Summer Course. Four teaching steps were implemented:

1) Working on a drama script.

2) Drama rehearsal.

3) Drama production.

4) Drama evaluation

For Data collection, speaking achievement tests were administered before and after students were exposed to drama and questioning techniques. A questionnaire was used at the end of the experiment to know students' attitude. Students and teachers' diaries were used as supplementary research tools to complement questionnaires. The t-test was incorporated to investigate to what extent drama and questioning techniques contribute in the improvement of students' scores. 
After analyzing the questionnaire using descriptive statistics focusing on the mean and the percentage, content analysis was implemented for the qualitative data which was extracted from students and teachers' diaries and the open -ended section of the attitude that deals with questionnaires. After comparing the results of the pretest and the post-test, it has been shown that the findings are significant. The results of the post-test are highly significant in comparison to the pre test (comparing the means). This implies that the implementation of drama and question techniques tend to boost students' speaking skill. Participating in Drama necessitates the integration of the four skills: reading, listening, speaking and writing that would improve their repertoire and mainly the speaking skills. The majority of students have been found to hold positive attitude towards the instruction delivered through the integration of drama and questioning techniques. Most of students agree that learning through the two techniques renders the lesson enjoyable and interesting. They enhance self-confidence, thinking skills, understanding the lesson and boosting their self-esteem. The instructors remarked that students have been active during the three teaching steps. The students' diaries prove the same. This study confirms the role of drama and questioning techniques in empowering students' language learning.

\subsubsection{Games}

Games play an important role in creating a relaxed atmosphere inside the classroom. They lessen students' anxiety and encourage not only extroverted learners, but introverted ones as well to participate and be active. Learning through fun makes the learners more attentive and aware of what is going on inside the classroom. Warschauer and Healey (1998) consider games as "the fun factor" of language learning. For this reason, several researchers argue that games enhance language learning, improve students' attitudes towards the course and seem to play a vital role in stimulating communication and communicative practices.

James Paul Gee (2003) delineates the importance of incorporating games in learning contending that:

"Learning is or should be both frustrating and life enhancing. The key is finding ways to make hard things life enhancing so that people keep going and don't fall back on learning and thinking only what is simple and easy." (p. 6).

Clark Aldrich (2005) elaborates more on the issue highlighting the three main components of successful educational experiences, namely simulation elements, game elements, and pedagogy elements. Simulation elements stand for the real world and student interactions with it; game elements offer entertaining and engaging elements that enhance learner motivation, and pedagogical elements assure that particular learning objectives are met.

In support of the same contention, Richards \& Rodgers (2001) explain that:

"A variety of games, role plays, simulations, and task-based communication activities have been prepared to support Communicative Language Teaching classes. These typically are in the form of one-of-a-kind items: exercise handbooks, cuecards, activity cards, pair-communication practice materials, and student-interaction practice booklets." (p. 169).

An action research was carried out by Huyen and Nga (2003) comparing between an experimental group for whom English was taught through games and a control group exposed to ordinary English classes. It was found that unlike students of the control group, students of the experimental group generally feel at ease and zealous to learn in classes in which games are incorporated. Learning vocabulary through games yields more results. Out of the 20 students surveyed, 18 among them expressed the view that the games were "one of the most effective ways of learning vocabulary."

Huyen and Nga (2003) observe in this connection "games contribute to vocabulary learning if they give students a chance to learn, practice and to review the English language in a pleasant atmosphere." They maintain the view that the relaxed atmosphere, friendly competitive context, and contextualization of vocabulary are some of the advantages of learning games in language teaching contexts.

Some researchers are more inclined to see games as a more facilitating factor to enhance the quality of learning. Baker (2000) contends in this respect that:

"Young children learn languages as naturally as they learn to run and jump, paint and play. Young children are not worried by their language mistakes, nor about not finding the exact words....Language acquisition is a by-product of playing and interacting with people." (p. 29).

More interesting perhaps, Shameem and Tickoo (1999, p. vii-viii) corroborate the same argument stating that:

"Learning takes place - even if incidentally - while the students are engaged 
in a self-motivating activity. They are having fun and interacting socially ( in pairs, in small groups, or with the whole class) to perform a task and reach a satisfactory outcome."

McCallum (1980) is more inclined to maintain the same contention adding that:

"... one recognizes the significant role of word games in achieving these objectives. Students, in the informal atmosphere of game play are less self-conscious and therefore more apt to experiment and freely participate in using the foreign language." (p. ix).

What follows from this is that students' process of language learning is best achieved when it is accomplished through games. As a matter of fact, students particularly in the informal atmosphere of game play are less self-conscious and therefore more apt to experiment and freely participate in using the foreign language.

Language learning games are meant to align with the tenets of learner-centered approaches to education. As such, students, according to Granger (1982), "will participate in lively, active lessons where they do most of the talking, and not the teacher." (p. 2). Perceiving the central role of games in education, Clark (1982) observes that they "are best used to review or practice words and sentences that have already been introduced. In a limited way, however, the games can be used to introduce new bits and pieces of language - especially vocabulary items and idioms." (p. 1).

Following the same line of reasoning, Yao \& McGinnis (2002) seem to capture the essence of games in promoting language learning argue that:

"Perhaps the best thing that can be said about these games for learning Chinese is that they are an extremely entertaining way to use the language. It is the word 'use' that is of paramount importance. There are numerous ways by which we can assess a student's ability to use the target language, be it memorized dialogues or written compositions. Yet these very means of purportedly promoting a student's progress in fact inhibits a portion of the student population. It is that portion that, intimidated by the pressures of a graded activity, may find the chance to freely practice without pressure, and to practice very well indeed, while playing these games" (p.494).

Hamzah and Dourado (2009) conducted an experimental study in a secondary school in Malaysia to investigate the feasibility of using language games as a research tool to teach grammar, namely the simple present tense and simple past tense.

Twenty-five learners were selected for the control group and thirty-one for the experimental group. The experimental group used games to learn grammar for four days; while, the control group did not receive any treatment. To gather data, students were assigned a pre-test and a post-test. Classroom observations were incorporated to determine learners' reaction to the use of games in enhancing communication, motivation and enthusiasm. Besides, interviews were carried out to discover ESL teachers' views regarding the incorporation of games to teach grammar.

The findings of this study tend to sustain the same vision concerning the pivotal importance of exploiting games in the teaching of languages. Students of the experimental group for whom the grammar course was taught through game plays were observed to find it easy to learn the simple present tense and the simple past tense, and they were also found to be more motivated and more enthusiastic while doing these activities and tasks.

\section{Methodology}

\subsection{Research Framework}

The current research is an experimental case study the purpose of which is to investigate the impact of 'Access Program' on the scholastic achievement of students of EFL at high school level in Morocco.

\subsection{Research Question}

The question that this paper is trying to answer is as follows:

- Does 'Access' microscholarship program, which includes a set of extracurricular activities, empower English language learners?

\subsection{Hypothesis}

- 'Access Program' empowers English language learning. 


\subsection{The population and Sampling procedures}

The population is first year high school Baccalaureate students in Morocco. The sampling is arranged between two groups of students. The sample includes students who have benefited from 'Access Program', (as an experimental group), and a group of students who did not have chance to benefit from the program (as a control group). At the beginning of the program, both groups include students sharing almost the same level as far as English is concerned (They all obtained marks which are not below 12/20). They were all beginners and being taught by the same teachers. They belong almost to the same social class; their parents are farmers, masons, drivers and so forth. Their age ranges between 16 and 18. The total number of the subjects is 110 students. They were identical at the beginning. Some of them (55 students) joined 'Access Program'; while, others did not. A convenient sampling was opted for as it was easy to have access to the following centers: Elhajeb, Midelt, Rich, Erfoud, Tiznit and Taroudant. In addition, teachers who were teaching those students belonging to both experimental and control groups were willing to cooperate and provide help when necessary. The number of the sampling in each center varies because some students were absent the day of the exam. It was obligatory to deal with the situation as it was.

Table 1: Distribution of respondents according to towns

\begin{tabular}{|l|l|l|}
\hline Town & Experimental group & Control group \\
\hline El-Hajeb & 15 & 15 \\
\hline Rich & 15 & 15 \\
\hline Erfoud & 7 & 7 \\
\hline Taroudant & 8 & 8 \\
\hline Tiznit & 10 & 10 \\
\hline
\end{tabular}

The 'Access Program' students have been taught using series of students' textbooks and workbooks called Mega 1, Mega 2, Mega 3, and Mega 4. These books are written by Chris Barked and Libby Mitchel and published by Macmillan Education. There is a balance in teaching the language skills. Each unit starts with teaching vocabulary and ends up by a project-work with much focus on some aspects of the American culture. The books are accompanied by CDs and DVDs as teaching aids. They are always exploited for listening activities to teach other skills. Students are provided by readers that contain either one short story or different short stories for the sake of extensive reading. Students are also allowed to use other technological devices like the computer, the video projector, the tape recorder and so on. These enhancement activities the experimental group was exposed to lasted for two hours a week and during a period of two years.

\subsection{The Research Instruments}

When the program was over, both groups (experimental and control) sat for a final exam. The test is used to extract quantitative findings. They were tested in listening comprehension, speaking, reading comprehension, writing and language. The questions are designed according to the curriculum of the first year Baccalaureat.

For the listening comprehension test, students were asked to fill in a table after listening to a dialogue between two people. For speaking, the criteria that were taken into consideration are fluency and accuracy. For reading comprehension, students were assigned a text about the internet and were asked to answer true or false questions, to complete sentences, and to give synonyms of words from the text. For language, students were asked to complete some sentences using given concepts. Next, they were assigned an exercise about functions (expressing purpose, concession, and clarification). After, they were asked to answer some questions about passive voice, simple past and past continuous, and the conditional type one. At the end, students were asked to write an essay either about the positive and negative points of the internet, or about the Revolutions.

\section{Presentation and results analysis}

Tests results have demonstrated that the experimental group have performed well in all tests, chiefly those that are concerned with performance and productivity (writing and speaking). This proves that the program has a great impact on students' linguistic abilities. The tables below depict a comparison between the two groups, incorporating descriptive statistics parameters processed using SPSS version 17. 


\subsection{Results of the Tests}

\subsubsection{Comparing parameters}

Table 2: Descriptive statistics of the Experimental Group

\begin{tabular}{|c|c|c|c|c|c|c|}
\hline & $\mathrm{N}$ & Minimum & Maximum & Mean & $\begin{array}{c}\text { Standard } \\
\text { Deviation }\end{array}$ & Variance \\
\hline listening marks & 55 & 10,00 & 20,00 & 17,6545 & 2,68720 & 7,221 \\
speaking marks & 55 & 10,00 & 19,00 & 16,6091 & 2,29672 & 1,275 \\
reading marks & 55 & 4,00 & 20,00 & 15,7455 & 4,03787 & 10,304 \\
writing markes & 55 & 4,00 & 19,00 & 15,7818 & 3,29810 & 1,718 \\
language marks & 55 & 6,00 & 20,00 & 14,8091 & 3,42308 & \\
N valide (listwise) & 55 & & & & & \\
\hline
\end{tabular}

Both tables (Table 2 and table 3) are used to compare the two groups. Descriptive statistics parameters are incorporated to compare the experimental and the control group. As a case in point, the mean is used to have a general idea about the level of both groups, and the coefficient of variance is used to check whether the scores are scattered or concentrated.

Table 3: Descriptive statistics of the Control Group.

\begin{tabular}{|c|c|c|c|c|c|c|}
\hline & $\mathrm{N}$ & Minimum & Maximum & Mean & Standard Deviation & Variance \\
\hline listening marks & 55 & 3,00 & 19,00 & 13,6818 & 3,62905 & 13,170 \\
speaking marks & 55 & 4,00 & 19,00 & 12,4545 & 3,80457 & 14,475 \\
reading marks & 55 & 2,00 & 19,00 & 8,9636 & 4,10945 & 16,888 \\
writing marks & 55 & 0,00 & 18,00 & 9,7455 & 4,03328 & 16,267 \\
language marks & 55 & 1,50 & 16,50 & 9,0364 & 3,49451 & 12,212 \\
N valide (listwise) & 55 & & & & & \\
\hline
\end{tabular}

For listening comprehension, students of the experimental group scored 10/20 as a minimal mark and 20/20 as a highest mark with a mean of 17.65 , and a standard deviation of 2,68. The control group; however, scored 03/20 as a minimal mark and 19/20 as a highest mark with a mean of 13.68 , and a standard deviation of 3,62 . This shows that the experimental group outperforms the control group since the mean of the first group is higher and its standard deviation is lower.

For speaking, students of the experimental group scored $10 / 20$ as a minimal mark and 19/20 as a highest mark with a mean of 16,60 , and a standard deviation of 2,29. The control group; on the other hand, scored $04 / 20$ as a minimal mark and $19 / 20$ as a highest mark with a mean of 12,45 and a standard deviation of 3,80 . There is a great difference between the two means to the advantage of the experimental group.

As for the reading comprehension test, students of the experimental group scored 04/20 as a minimal mark and 20/20 as a highest mark with a mean of 15,74 , and a standard deviation of 4,03 . For the control group; however, the lowest score is only $02 / 20$ and the highest score is $19 / 20$ with a mean of 08.98 , and a standard deviation of 4,10 . Although the standard deviation is almost the same, there is a significant difference between the means of the two groups. This means that there is a concentration of scores in 
both groups. Yet, most scores in the experimental group are around 15/20; while, most of the control group marks revolve around merely 09/20.

In Writing, 'Access Program' students obtained $04 / 20$ as the lowest score and 19/20 as a highest one. The mean of this group is 15,78 and the standard deviation is 3.92. With respect to the 'Non- Access Program' students, the minimal score is $00 / 20$ and the highest one is 18 . The mean of those students is 9.74 and the standard deviation is 04.03 . Comparing the means of the two groups shows clearly the superiority of the experimental over the control one. The standard deviation here does in no way mean that there is a similarity between the two groups since there is a huge difference between the two means.

For language, the experimental group scored $06 / 20$ as a minimal mark and $20 / 20$ as a highest mark. The mean of this group is 14.80 and the standard deviation is 3.42. As far as the control group is concerned, the minimal score is $01.50 / 20$ and the highest one is 16.50 . The mean of these students is merely 9.03 and the standard deviation is 03 . 49. The difference between the two groups is obvious as the experimental group's mean is 14,80 while that of the control group is only 9.03.

It follows from this that students who have benefited from 'Access Program' have obtained high mean scores in comparison to the group of students who did not. The first group seems to display a homogeneous status since its students' marks are not scattered. The second group who has not been exposed to the same treatment 'Access Program' has obtained below average means in the sections pertaining to such tasks as reading comprehension, language and writing. Although the control group scores in listening and speaking are fairly good, the experimental group scores are much better.

\subsubsection{Comparing the mean scores of the experimental and the control groups.}

As one may observe from table 4 below, there is a general presentation of results comparing between the mean of both groups regarding their obtained scores in listening comprehension, speaking, reading comprehension, language and writing. Students of the experimental group obtained 16.12 as a mean and the minimal mean score is 8.80 and the maximal score is 19.60 with a standard deviation of 2.61. Students of the control group; however, scored 10.78 as a mean and have 5.20 as a minimal mark and 18,20 as a maximal mark with a standard deviation of 3.16 .

Table 4: Comparison of the two groups' mean scores.

\begin{tabular}{|c|c|c|c|}
\hline & & Non-access & Access \\
\hline \multirow[t]{2}{*}{$\mathrm{N}$} & Valid & 55 & 55 \\
\hline & Missing & 0 & 0 \\
\hline \multicolumn{2}{|c|}{ Mean } & 10,7875 & 16,1200 \\
\hline \multicolumn{2}{|c|}{ Median } & 10,7000 & 16,8000 \\
\hline \multicolumn{2}{|c|}{ Std. Deviation } & 3,16734 & 2,61310 \\
\hline \multicolumn{2}{|c|}{ Minimum } & 5,20 & 8,80 \\
\hline \multicolumn{2}{|c|}{ Maximum } & 18,20 & 19,60 \\
\hline
\end{tabular}

For more clarity in the achievement test results between the two sampled groups, let us consider the following two histograms. The histogram of 'Access Program' students shows that the majority of the mean scores are arranged between 14/20 and 19/20. This indicates that the overall scores of this group are all of them good. 
Histogram of 'Access Program' scores:

\section{Histogram}

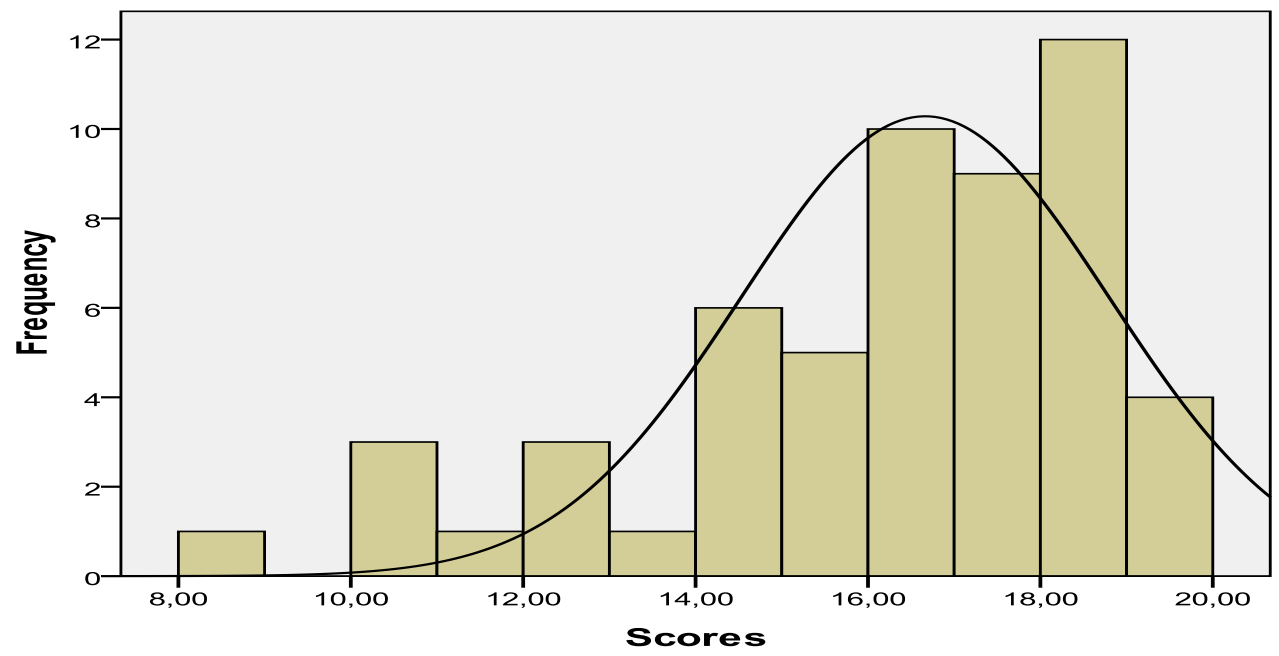

Mean $=16,12$
Std. Dev. $=2,613$
$N=55$

Figure 1: Experimental group mean scores

For 'Non-Access Program' students, histogram in figure 2 delineates clearly that their mean scores range merely between $09 / 20$ and $14 / 20$.

Histogram of 'Non-Access Program' scores:

Histogram

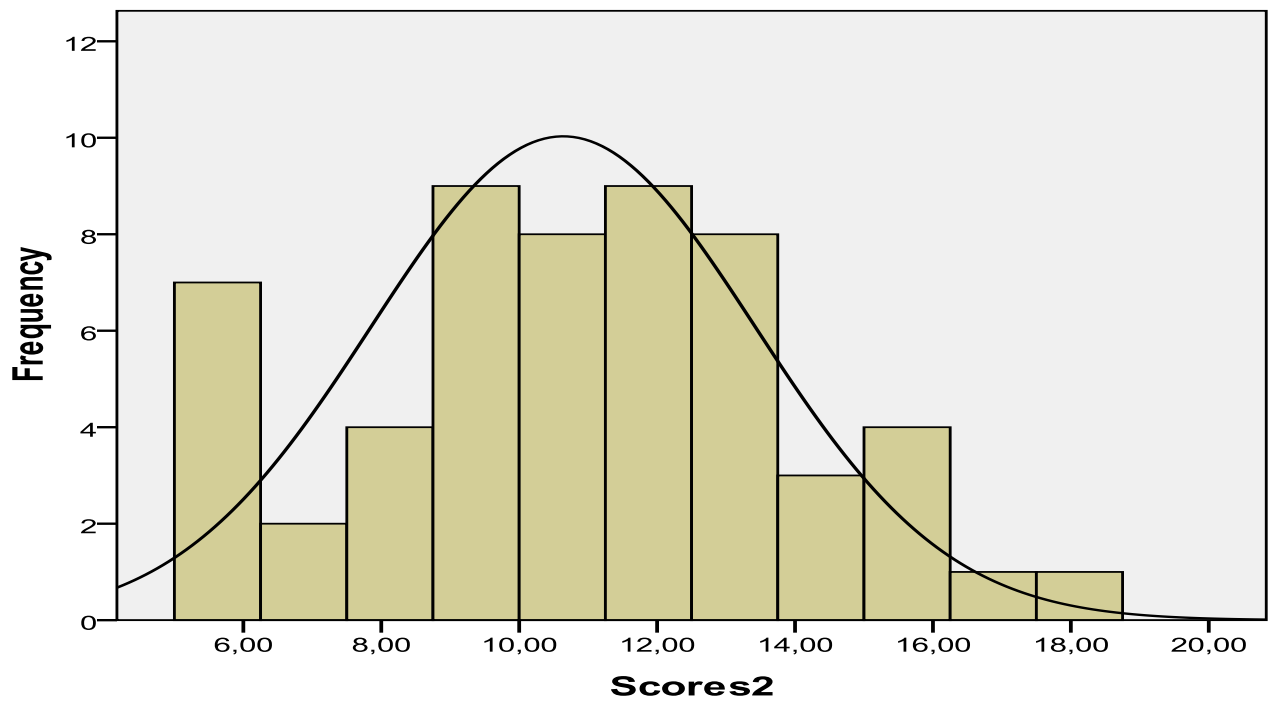

Mean $=10,79$
Std. Devis $=3,167$
$N=56$

Figure 2: Control group mean scores.

Briefly stated, the findings prove that the students who were exposed to 'Access Program' have outperformed the students who did not. The program seems to have substantially influenced learners' performances at almost all the language achievement tests under study. 'Access Program' students have been observed to surpass their 'Non-Access Program' peers along the five achievement tests. 
4.2 Correlation between the skills

4.2.1 Correlation between the skills among 'Access' Students

Table 5: Correlation between the skills

\begin{tabular}{|l|l|l|}
\hline & listening marks & speaking marks \\
\hline Pearson Correlation & &, $547^{\star *}$ \\
\hline & reading marks & writing marks \\
\hline Pearson Correlation & &, $537^{\star *}$ \\
\hline & writing marks & Language marks \\
\hline Pearson Correlation & &, $698^{\star *}$ \\
\hline & language marks & reading marks \\
\hline Pearson Correlation & &, $591^{\star *}$ \\
\hline
\end{tabular}

**. Correlation is significant at the 0.01 level (2-tailed).

The table demonstrates that there is a positive correlation between speaking and listening comprehension, reading and writing, writing and language, and language and reading. Correlation between writing scores and language is more positively significant (0.698) in comparison to the previous skills mentioned above. This could prove that students who are good at writing are good at language. Indeed, language helps learners a great deal to write correct structures. Correlation is classified as large because the ( $r$ ) value is beyond 0,50. According to Cohen's guidelines (1988, pp. 79-81) correlation is classified as follows:

Small $\quad r=.10$ to .29

Medium $\quad r=.30$ to .49

Large $\quad r=.50$ to 1.0

The majority of the scores are concentrated between the interval $[15,20]$. This shows that there is a positive correlation between the different skills. It reveals also that access students are good at the five studied skills. This, in turn, demonstrates the important impact of this microscholarship program on the amelioration of students' progress in those skills.

\subsubsection{Correlation between the skills among 'Non-Access' Students}

Table 6: Correlation between the skills.

\begin{tabular}{|l|l|l|}
\hline & listening marks & speaking marks \\
\hline Pearson Correlation & &, $562^{\star *}$ \\
\hline Pearson Correlation & reading marks & writing marks \\
\hline & writing marks &, $612^{\star *}$ \\
\hline Pearson Correlation & & Language marks \\
\hline & language marks & reading marks \\
\hline Pearson Correlation & &, $646^{\star *}$ \\
\hline
\end{tabular}

**. Correlation is significant at the 0.01 level (2-tailed). 
The value of correlation between all the skills is nearly the same as the one in the experimental group. There is a positive correlation between all the skills. According to the analyzed tables, correlations are positive and significant between all the skills (as one variable increase so does the other).

On the other hand, the students who performed low in a skill did the same in the others. This means that students who have difficulties at any specific skill still encounter difficulties in other skills. Students who excel in some skills; however, tend to excel in the others too. The findings confirm the hypothesis of this study substantiating the view that the extracurricular activities of the 'Access Program' present students with more rewarding assets conducive to the empowerment of their achievement levels in English.

\section{Conclusion and Recommendations}

Based on the findings drawn from the achievement tests of both groups, and relying on classroom observations, the following conclusions are drawn:

- The respondents enjoyed attending 'Access Program' classes.

- The respondents liked to share their ideas and information with others.

- Access helps the respondents to pass their examination.

- The respondents enjoy microscholarship programs.

- The respondents can gain a lot of knowledge and new experiences.

- Extracurricular activities release students' tension and stress.

- The respondents do not get bored easily when learning English using different activities.

- Extracurricular activities make learning more fun and interesting.

- The respondents were happy, excited, and enjoyed themselves when carrying out a project work.

- The classroom participation level was increased during extracurricular activities.

- Access microscholarship program enabled students to acquire English language.

- Extracurricular activities create more caring, supportive, and committed relationships.

The findings of this study prove that extracurricular activities can increase students' achievement levels in English. They can bring positive effects on academic achievement and on the social relationships among all students. Extracurricular activities seem to promote higher achievement among students along with an increase in their motivation.

The majority of the students would benefit both socially and academically if extracurricular activities are implemented in the classroom context. These supplementary activities cannot only enhance students' achievement in English but can also help maximize their performance capabilities as well as heighten their interpersonal skills needed for success in school and society at large.

\section{Pedagogical Implications}

From the results and findings, some recommendations are suggested for both teachers and policy-makers. First, teachers should volunteer to participate actively in extracurricular activities since students benefit a great deal from them and get the academic support that will help them excel in their studies.

Second, policy-makers should offer more microscholarship programs particularly to underprivileged students. More partnership agreements should be signed by some foreign organizations, non-governmental associations, and the government with the ultimate objective to sponsor some scholarship programs that would undoubtedly be of great benefit mainly to the disadvantaged groups of society.

\section{Limitation and Suggestions for Further Research}

Any piece of research cannot be accomplished without limitations. One of the limitations of this paper is the small sample size. It is hard to control the variables in humanities area. There might be other extraneous variables that may intervene in reshaping the findings. Time constraints may also impede conducting an exhaustive research since longitudinal studies require more time and more rigors to be implemented. Data should be conducted at the end of each term, which is neither easy nor practical to undertake.

Additional research should be conducted to examine whether these results are positive in a large sample in all forms, all disciplines, in urban, in rural, in suburban schools, and for high, average, and low achievers.

Further, it would be interesting to do further research into whether extracurricular activities promote better retention of knowledge gained after teaching. For better results, the teacher could give a post-test after each term of implementing extracurricular activities. 
Before any definitive conclusions could be made, it is recommended that more research avenues should be carried out to verify the findings of the current study in order to strengthen this contribution towards the development of a sound research data, based on extracurricular activities.

\section{Abut Authors}

Said Aoujil is a PhD candidate and a part-time teacher at the Department of English, Faculty of Arts and Humanities, Meknes, Morocco. His research interests revolve around such areas as Applied Linguistics, EFL learning and teaching, and Research on students' writings.

Driss Benattabou is a professor of English at the Department of English, Faculty of Arts and Humanities, Meknes, Morocco. He holds a PhD from Moulay Ismail University, Meknes, Morocco. He has published a number of articles in such research areas as Applied Linguistics, Gender in Education, Critical Discourse Analysis and Visual semiotics.

Funding: This paper has not received any funding.

Conflicts of Interest: The authors declare no conflict of interest.

\section{References}

[1] Arévalo, E. (2010). The use of songs as a tool to work on listening and culture in EFL Classes. Cuadernos de Lingüística Hispánica, 15, 121138.

[2] Baker, C (2000). The Care and Education of Young Bilinguals: An Introduction forProfessionals. Bristol Multilingual Matters.

[3] Brand, M. \& Li, X. (2009). "Effectiveness of music on vocabulary acquisition, language usage, and meaning for mainland Chinese ESL learners". Contributions to Music Education, 36(1), 73-84

[4] Clark, R.C. (ed.) (1982). Index Card Games for ESL. Brattleboro: Pro Lingua Associates.

[5] Granger, C. (1982). Play Games with English (Teacher's Book). London: Heinemann Educational Books Ltd.

[6] Huyen, N.T.T. \& Nga, K.T.T. (2003). "The effectiveness of learning vocabulary through games". Asian EFL Journal, December 2003. Retrieved on May 10, 2019 from http:// www.asian-efl-journal.com/dec 03 sub.Vn.php

[7] Janudom, R., \& Wasanasomsithi, P. (2009). Drama and questioning techniques: Powerful tools for the enhancement of students' speaking abilities and positive attitudes towards EFL learning. ESP World, 8(5), 23-28.

[8] Ling, L , C. (2009). An evaluation of a school based English Language Curriculum initiative on the teaching of songs: a primary school case study. [Unpublished MA Dissertation].

[9] McCallum, G.P. (1980). 101 Word Games. New York: Oxford University Press.

[10] Medina, S.L. (2003). "Acquiring English Through Story-songs." MEXTESO (Mexican Teachers of English to Speakers of English and Other Languages). Language Journal.

[11] Hamzah, M \& Dourado, J (2009). Using Grammar Games in Teaching Grammar: A Case Study in Smkd Damai Jaya. Retrieved on January 12 , 2019 from core.ac.uk.

[12] Richards, J. \& Rodgers, T. (2001). Approaches and methods in language teaching

[13] Şevik, M. (2012). "Developing young learners'listening skills". Kastamonu Educational Journal, (1), 327-340 (2nd Ed.): Cambridge University Press.

[14] Shameem, N. \& Tickoo, M. (Eds.) (1999). New ways in using communicative games in language teaching. Alexandria, VA : Teachers of English to Speakers of Other Languages, Inc.

[15] Vygotsky, L. (1987). Thought and Language. Cambridge, MA: Harvard University Press.

[16] Vygotsky, L.S. (1987). Mind in Society: The Development of Higher Psychological Processes. Cambridge: Harvard University Press.

[17] Wray, A., \& Perkins, M. (2000). "Functions of Formulaic Language". Language and Communication, 20, pp. 1-28. From http://dx.doi.org/10.1016/S0271- 5309(99)00015-4. Retrieved on July 22nd 2020

[18] Yao, T \& Mginnis, S (2002). Let's Play Games in Chinese. Boston, Cheng Tsui. 